Journal of Mathematics and Statistics 3 (4): 263-267, 2007

ISSN 1549-3644

(C) 2007 Science Publications

\title{
Numerical Study on the Effect of Linear Friction of Long-Wave Propagation and Breaking with Sloping Bottom
}

\author{
Agustinus Ribal \\ Department of Mathematics, Faculty of Science, Hasanuddin University, P.O. 90245, \\ Makassar, Indonesia
}

\begin{abstract}
In this study, we investigate the breaking of long-waves propagating on shallow water with linear friction on the sloping bottom. A complete set of equations is presented and a numerical method is developed to simulate the wave propagation. The method uses an up-wind difference scheme for the nonlinear convective term and the central difference scheme for other derivative terms. Various numerical examples have been conducted to investigate the effect of friction coefficient and drag coefficient on wave propagation and breaking.
\end{abstract}

Keywords: Friction, wave breaking, partial differential equations

\section{INTRODUCTION}

Long-wave breaking on shallow water with a sloping bottom has been a matter of interest for most scientists over the last two centuries. Many attempts have been made to investigate and model such breaking. The first significant contribution was made by Carrier and Greenspan ${ }^{[3]}$ who investigated the behaviour of a wave as it climbs up a sloping beach with no friction on the bottom. Okeke ${ }^{[14]}$ investigated long-wave breaking on a sloping beach with governing linear differential equations. Kurkin and Pelinovsky ${ }^{[11]}$ studied the mechanism of the spatial-temporal focusing of the edge waves in the self zone and proposed to find the localized anomalous high wave generating in the process of the wave packet focusing. Recently, $\mathrm{Li}$ and Jeng $^{[12]}$ used the conventional Kortegweg-de Vries $(\mathrm{KdV})$ equation to discuss the phenomena of nonlinear water wave propagation above the seabed with variable depth. However, friction on the bottom was not considered in the above papers, and consequently the results obtained do not agree well with the real wave propagation behaviour, particularly for the propagation of waves in the shallow water region. A very significant contribution on the study of the effect of bottom friction is due to $\mathrm{Wu}$ and $\operatorname{Tian}^{[26]}$, who studied the breaking of long waves propagating along an open channel with linear friction on the even bottom and derived an analytical solution for the estimation of breaking time and location. Based on Wu and Tian's work, this paper conducts an extensive numerical investigation to investigate the effect of bottom friction on wave propagation and breaking on shallow water with sloping bottom.

\section{GOVERNING EQUATIONS}

For the case where the undisturbed water depth is a linear function of the horizontal $\mathrm{x}$ coordinate as shown in Fig. 1.

The governing equations are as follows:

$$
\begin{aligned}
\frac{\partial \mathrm{u}}{\partial \mathrm{t}}+ & \mathrm{u} \frac{\partial \mathrm{u}}{\partial \mathrm{x}}+\mathrm{g} \frac{\partial}{\partial \mathrm{x}}(\xi(\mathrm{x}, \mathrm{t}))=-\frac{\mathrm{ku}}{\mathrm{h}(\mathrm{x})+\xi(\mathrm{x}, \mathrm{t})}, \\
& \frac{\partial}{\partial \mathrm{t}}(\mathrm{h}(\mathrm{x})+\xi(\mathrm{x}, \mathrm{t}))+(\mathrm{h}(\mathrm{x})+\xi(\mathrm{x}, \mathrm{t})) \frac{\partial \mathrm{u}}{\partial \mathrm{x}} \\
& +\mathrm{u} \frac{\partial}{\partial \mathrm{x}}(\mathrm{h}(\mathrm{x})+\xi(\mathrm{x}, \mathrm{t}))=0
\end{aligned}
$$

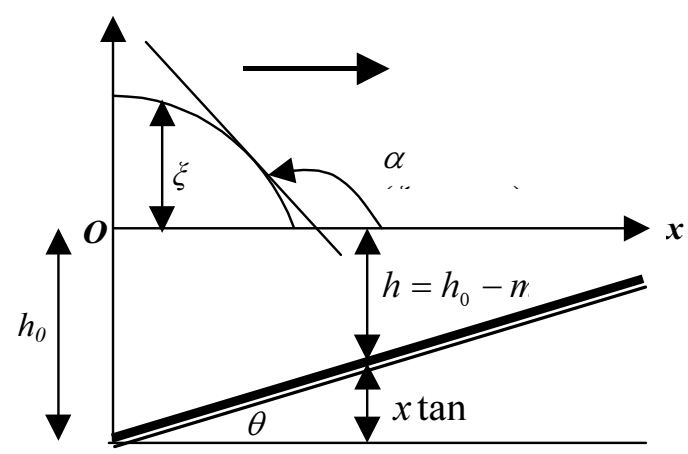

Fig. 1: Wave profile and coordinate system 
where $h(x)=h_{0}-m x, \quad m=\tan \theta, \quad u=u(x, t)$ is the horizontal component of water velocity, $\mathrm{h}$ and $\xi(x, t)$ represent respectively the undisturbed water depth and the water surface elevation, $g$ denotes the gravitational acceleration, $\mathrm{k}$ is the drag coefficient, $\mathrm{x}$ and $\mathrm{t}$ are respectively horizontal coordinate and time.

\section{NUMERICAL SCHEME}

The governing equations for the problem in question can be written as:

$$
\begin{aligned}
& \frac{\partial u}{\partial t}+u \frac{\partial u}{\partial x}+g \frac{\partial \xi(x, t)}{\partial x}+\frac{k u}{h(x)+\xi(x, t)}=0, \\
& \frac{\partial \xi(x, t)}{\partial t}+\frac{\partial}{\partial x}[(h(x)+\xi(x, t)) u]=0 .
\end{aligned}
$$

For the following time derivatives, we use the forward difference scheme,

$$
\begin{gathered}
\frac{\partial u}{\partial t} \approx \frac{u_{i, j+1}-u_{i, j}}{\Delta t}, \\
\frac{\partial \xi}{\partial t} \approx \frac{\xi_{i, j+1}-\xi_{i, j}}{\Delta t} .
\end{gathered}
$$

For the following spatial derivatives, we use the central difference scheme,

$$
\begin{aligned}
& \frac{\partial u}{\partial x} \approx \frac{u_{i+1}-u_{i-1}}{2 \Delta x} \\
& \frac{\partial}{\partial x}[(h+\xi) u] \approx \frac{\left(h_{i+1}+\xi_{i+1}\right) u_{i+1}-\left(h_{i-1}+\xi_{i-1}\right) u_{i-1}}{2 \Delta x},(6) \\
& \frac{\partial}{\partial x}(\xi) \approx \frac{\xi_{i+1}-\xi_{i-1}}{2 \Delta x}
\end{aligned}
$$

Thus by substituting (7) and (6) into (2), we obtain,

$$
\xi_{i}^{1}=\xi_{i}-\Delta t\left\{\frac{\left(h_{i+1}+\xi_{i+1}\right) u_{i+1}-\left(h_{i-1}+\xi_{i-1}\right) u_{i-1}}{2 \Delta x}\right\} .
$$

For the nonlinear convective term $u \frac{\partial u}{\partial x}$, we use the upwind difference scheme. By using Taylor's theorem, the forward and backward difference formulae can be obtained respectively as follows:

$$
\begin{aligned}
& \frac{d u}{d x} \approx \frac{u_{i+1}-u_{i}}{\Delta x}=u^{+}, \\
& \frac{d u}{d x} \approx \frac{u_{i}-u_{i-1}}{\Delta x}=u^{-} .
\end{aligned}
$$

The upwind difference scheme is defined by:

$u \frac{\partial u}{\partial x}=u u^{*}$

where

$$
u^{*}=\left\{\begin{array}{lll}
u^{-} & \text {; if } & u>0 \\
u^{+} & ; \text {if } & u<0
\end{array}\right.
$$

where $u^{+}$and $u^{-}$are defined by (9a) and (9b).

For convenience in presentation, we introduce the sign function as below

$$
\operatorname{sgn}(u)=\frac{|u|}{u}
$$

Thus,

$$
u_{i}^{1}=u_{i}-\Delta t\left\{\frac{1}{2 \Delta x}\left\{\begin{array}{l}
\left(u_{i}-\left|u_{i}\right|\right)\left(u_{i+1}-u_{i}\right) \\
+\left(u_{i}+\left|u_{i}\right|\right)\left(u_{i}-u_{i-1}\right) \\
+g\left(\xi_{i+1}-\xi_{i-1}\right)
\end{array}\right\}+\frac{k u_{i}}{h_{i}+\xi_{i}}\right\} \text {. }
$$

Therefore, the finite difference scheme can be written as follows:

$$
\begin{aligned}
& \mathrm{u}_{\mathrm{i}}^{1}=\mathrm{u}_{\mathrm{i}}-\Delta \mathrm{t}\left\{\frac{1}{2 \Delta \mathrm{x}}\left\{\begin{array}{l}
\left(\mathrm{u}_{\mathrm{i}}-\left|\mathrm{u}_{\mathrm{i}}\right|\right)\left(\mathrm{u}_{\mathrm{i}+1}-\mathrm{u}_{\mathrm{i}}\right) \\
+\left(\mathrm{u}_{\mathrm{i}}+\left|\mathrm{u}_{\mathrm{i}}\right|\right)\left(\mathrm{u}_{\mathrm{i}}-\mathrm{u}_{\mathrm{i}-1}\right) \\
+\mathrm{g}\left(\xi_{\mathrm{i}+1}-\xi_{\mathrm{i}-1}\right)
\end{array}\right\}+\frac{k u_{i}}{h_{i}+\xi_{i}}\right\}, \\
& \xi_{i}^{1}=\xi_{i}-\Delta t\left\{\frac{\left(h_{i+1}+\xi_{i+1}\right) u_{i+1}-\left(h_{i-1}+\xi_{i-1}\right) u_{i-1}}{2 \Delta x}\right\}
\end{aligned}
$$
2.

where all of the variables are as defined in section

\section{NUMERICAL RESULTS}

Letting $\quad h_{0}=10$ meters, we have $h(x)=10-m x$ where $m=\tan \theta$ and the initial water level disturbance is chosen as ${ }^{[26]}$. 


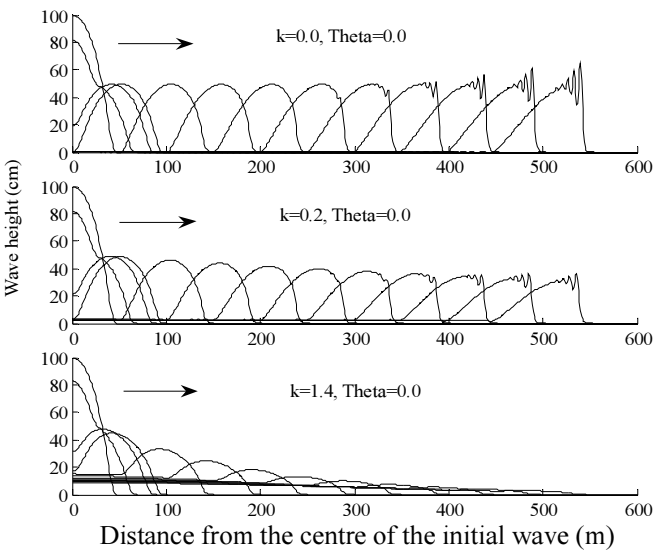

Fig. 2: Numerical results of evolution of long-waves for $\theta=0.0$ with different drag coefficients

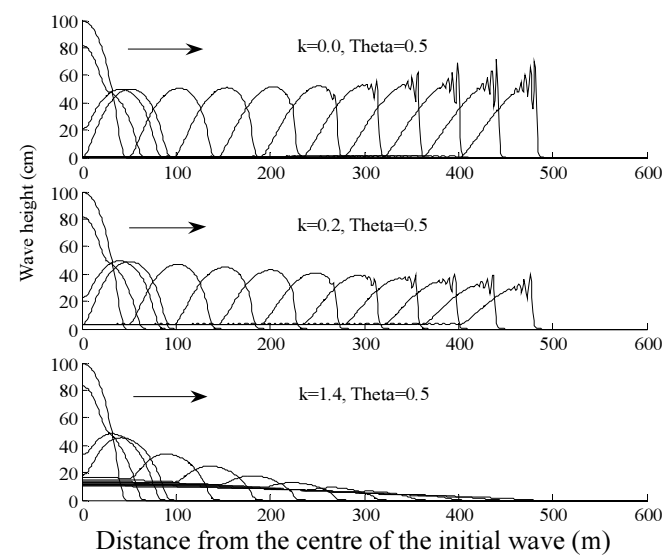

Fig. 3: Numerical results of evolution of long-waves for $\theta=0.5$ with different drag coefficients

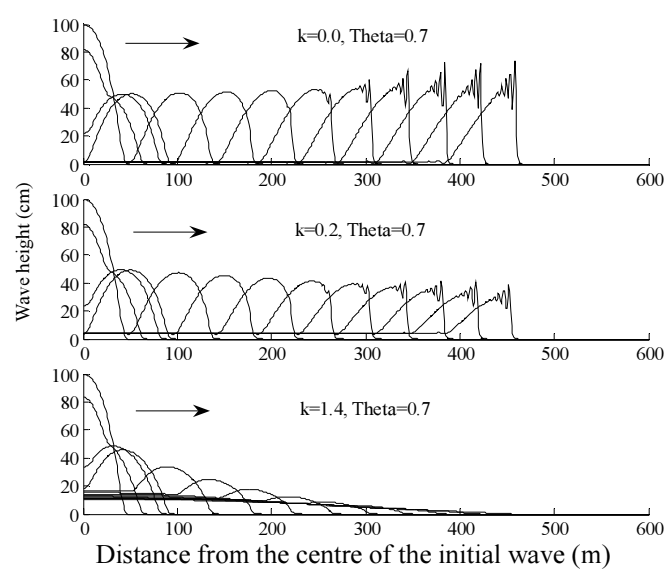

Fig. 4: Numerical results of evolution of long-waves for $\theta=0.7$ with different drag coefficients

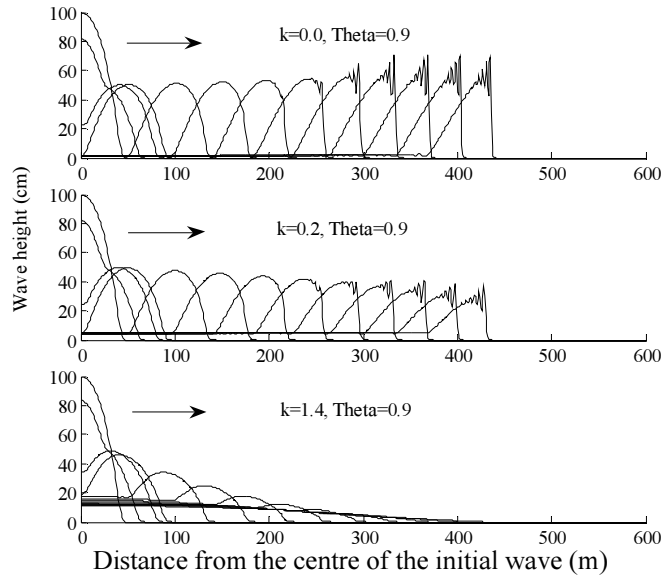

Fig. 5: Numerical results of evolution of long-waves for $\theta=0.9$ with different drag coefficients

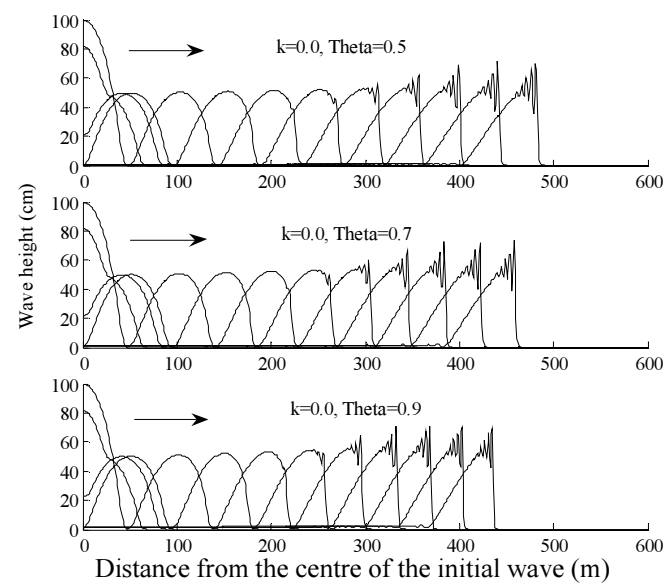

Fig. 6: Numerical results of evolution of long-waves for $\mathrm{k}=0.0 \mathrm{~m} / \mathrm{s}$ with different $\theta$

$$
\xi(x, 0)= \begin{cases}\exp \left(-\frac{x^{2}}{50^{2}-x^{2}}\right) & ; 0<|x|<50 \\ 0 & ;|x| \geq 50\end{cases}
$$

The numerical results for the problem considered here are as follows. The vertical axis and the horizontal axis represent, respectively, wave height $(\mathrm{cm})$ and distance from the centre of the initial wave $(\mathrm{m})$ respectively.

Fig. 2-5 show the effect of linear friction on long-wave propagation and breaking with different slope on the sloping bottom. These results also agree with the results obtained by $\mathrm{Wu}$ and Tian for the case with even bottom. Fig. 6-8 show the influence of slope on the long 


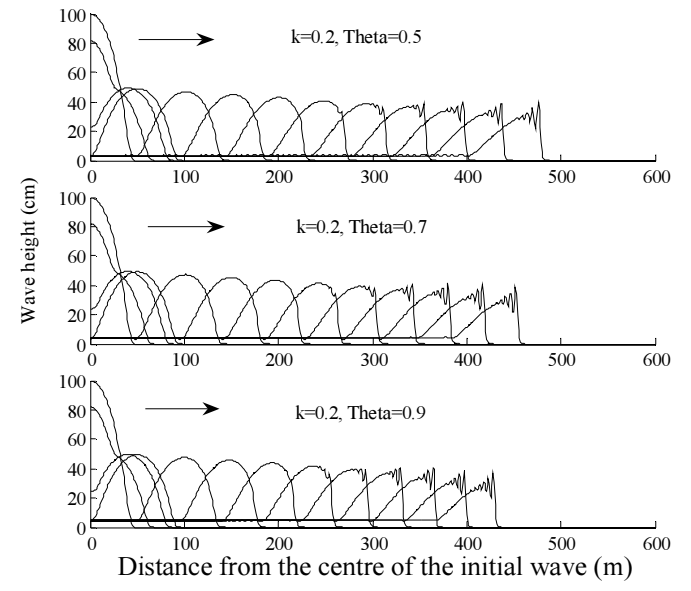

Fig. 7: Numerical results of evolution of long-waves for $\mathrm{k}=0.2 \mathrm{~m} / \mathrm{s}$ with different $\theta$

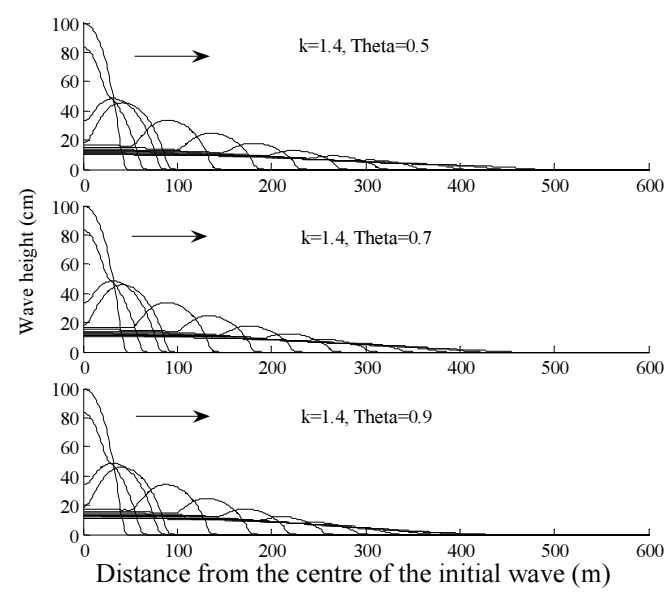

Fig. 8: Numerical results of evolution of long-waves for $\mathrm{k}=1.4 \mathrm{~m} / \mathrm{s}$ with different $\theta$

wave propagation and breaking. As noted from the Figs., if the slope of the bottom increases, the distance from the centre of the initial wave to the location where wave breaking occurs decreases. This is in agreement with reality: the slope of beaches affects the distance from the source to the beach.

\section{CONCLUSION}

We have successfully simulated the effect of the linear friction on the evolution of long wave propagation and breaking for the case with sloping bottom. If the drag coefficient is less than the critical value, long wave breaking will take place. However, if the drag coefficient is greater than the critical value, long-wave breaking will not occur. This is because for the large drag coefficient, the diffusion due to the bottom friction is predominant and the motion energy of the long-waves is gradually exhausted. It has also been found that with the increase in the slope of the bottom, the breaking time and the distance from the initial wave to the location where wave breaking takes place decrease.

\section{ACKNOWLEDGEMENT}

The author is grateful to Professor Yong Hong Wu of the Curtin University of Technology for his supervision of the research project and his advice and suggestions in the preparation and writing of this paper.

\section{REFERENCES}

1. Bleistein, N., 1984. Mathematical Methods for Wave Phenomena, Academic Press INC., San Diego.

2. Carmo, JSAD, Seabra-Santos, FJ and AmadoMendes, P 2002, 'Sudden bed changes and wavecurrent interactions in coastal regions', Advanced in Engineering Software, No. 33: 97-107.

3. Carrier, G.F. and H.P. Greenspan, 1957. Water waves of finite amplitude on a sloping beach' J. of Fluid Mechanics, vol. 4: 97-112.

4. Debnath, L., 1997. Nonlinear Partial Differential Equations For Scientists and Engineers, Birkhauser, Boston.

5. Ferziger, J.H. and M. Peric, 1999. Computational Methods for Fluid Dynamics, 2 edn, SpringerVerlag, Berlin.

6. Giordano, F.R. and M.D. Weir, 1991. Differential Equations: A Modeling Approach, AddisonWesley Publishing Company, New York.

7. Johnson, H.K., T.V. Karambas, I. Avgeris, B. Zauttigh, D. Gonzales-Marco and I. Caceres, 2005. Modelling of waves and currents around submerged breakwaters, Coastal Engineering, No. 52: 949-969.

8. Johnson, R.S. 1997. A Modern Introduction to the Mathematical Theory of Water Waves, Cambridge University Press, Cambridge.

9. Karambas, T.V. and C. Koutitas, 1992. A breaking wave propagation model base on the Boussinesq equations, Coastal Engineering, No. 18: 1-19.

10. Komen, G.J., L. Cavalery, M. Donelan, K. Hasselmann, S. Hasselmann and Janssen, PAEM 1994. Dynamics and Modelling of Ocean Wave, Cambridge University Press, Cambridge. 
11. Kurkin, A. and E. Pelinovsky, 2002. Focusing of edge waves above a sloping beach, European J. of Mechanics, 21: 561-577.

12. Li, J. and D.S. Jeng, Note on the propagation of a shallow water wave in water of variable depth. Ocean Engineering (2006), doi:10.1016/j.oceaneng. 2006.08.010

13. Mader, C.L. 1988. Numerical Modeling of Water Waves, University of California Press, Los Angeles.

14. Okeke, E.O. 1983. On the Linearized Shallow Water waves over the sloping bottom, IL Nuovo Cimento, No. 1: 72-82.

15. Pain, H.J. 2005. The Physics of Vibrations and Waves, 6 edn, John Wiley and Sons Ltd., West Sussex.

16. Pelinovsky, E, A.V. Rasin and E.V Sasorova, 1998. Berkhoff Approximation in a problem on surface gravity wave propagation in a basin with bottom irregularities, Wave in Random Media, vol. 8: 255-268.

17. Pelinovsky, E.N. and R.K. Mazova, 1992. Exact Analytical Solution of Nonlinear Problems of Tsunami Wave Run-up on slopes with Different profiles, Natural Hazards, 6: 227-249.
18. Rahman, M. 1995. Water Waves: Relating Modern Theory to Advanced Engineering Applications, Oxford University Press Inc., New York.

19. Rogers, S.E. and D. Kwak, 1991. An Upwind differencing scheme for the incompressible Navier-Stokes equations, Applied Numerical Mathematics, 8: 43-64.

20. Smith, G.D. 1985. Numerical Solution of Partial Differential Equations: Finite Difference Methods, 3 edn, Oxford University Press, New York.

21. Stoker, J.J. 1957. Water Waves, Interscience Publishers, Inc., New York.

22. Toda, M. 1989. Nonlinear Waves and Solitons, KTK Scientific Publishers, Tokyo.

23. Verhulst, F. 1996. Nonlinear Differential Equations and Dynamical Systems, 2 Edn, Springer-Verlag, Berlin.

24. Vreugdenhil, C.B. 1994. Numerical Methods for Shallow-Water Flow, Kluwer Academic Publishers, Dorddrecht.

25. Whitham, G.B. 1974. Linear and Nonlinear Waves, John Wiley and Sons, New York.

26. Wu, Y.H. and J.W. Tian, 2000. Mathematical analysis of long wave breaking on open channels with bottom friction, Ocean Engineering, 187-201. 